\title{
Is altered atrial microRNA-ome a critical contributor to the pathophysiology of atrial fibrillation?
}

\author{
Dobromir Dobrev
}

Received: 3 July 2012/Accepted: 4 July 2012 / Published online: 17 July 2012

(C) Springer-Verlag 2012

Atrial fibrillation (AF) is the most frequent arrhythmia in the clinical setting and is associated with substantial cardiac morbidity and mortality [19]. Current drug interventions have limited efficacy and are accompanied by significant risk of proarrhythmic events [9]. The generally poor outcome with current antiarrhythmic drugs likely reflects the fact that most of the used agents were developed in the absence of precise understanding of pro- and anti-arrhythmic drug actions and the arrhythmogenic disease-specific cardiac substrate. Conceptually, AF induction requires a vulnerable substrate and a trigger that acts on the substrate to initiate the arrhythmia [25, 35]. Once AF is initiated, the rapid-atrial rate creates progressive AF-related changes in atrial electrical and structural properties (atrial remodeling). Electrical remodeling involves a shortening of the atrial effective refractory period (AERP) and abnormal atrial $\mathrm{Ca}^{2+}$ signaling, whereas increased atrial fibrosis and heterogeneous conduction slowing are typical characteristics of structural remodeling. Atrial remodeling can promote ectopic (triggered) activity and facilitate reentry, thereby contributing to AF perpetuation and the progression from short-lasting (paroxysmal) to long-standing persistent AF [7, 10, 25, 26, 35], which makes AF more resistant to both pharmacological and nonpharmacological therapeutic approaches. Therefore, it is assumed that a better understanding of the molecular mechanisms underlying AF maintenance will help to

This invited editorial is related to the original contribution available at doi:10.1007/s00395-012-0278-0.

\section{Dobrev $(\square)$}

Division of Experimental Cardiology, Medical Faculty

Mannheim, Heidelberg University, Theodor-Kutzer-Ufer 1-3, 68167 Mannheim, Germany

e-mail: dobromir.dobrev@medma.uni-heidelberg.de design novel drugs with improved efficacy and safety profiles [8].

The mechanisms contributing to ectopic activity and reentry during AF are incompletely understood. Recent studies have provided compelling evidence that alterations in atrial microRNA ( $\mathrm{miR}$ ) expression could contribute to the basic mechanisms of AF [36]. MiRs are small (20-25 nucleotides) non-coding RNAs that bind to complementary sequences in the $3^{\prime}$ untranslated regions of target mRNA in a sequence-specific manner, usually resulting in gene silencing by either blocking translation or directing degradation [20, 27]. They act in a complex functional network in which individual miRs can control hundreds of genes and a single gene can be regulated by multiple miRs. Because miRs are central players in the regulation of gene expression, they participate in many physiological processes, including differentiation, proliferation, migration, metabolism, apoptosis and cell death. Therefore, it is not surprising that miR dysfunction plays a critical role in the pathogenesis of cardiovascular diseases [24].

In this issue of the journal, Adam et al. [2] show that miR-21, which was previously shown to play a crucial role in cardiac remodeling by affecting ERK-MAP kinase signaling in ventricular fibroblasts [31], is a critical regulator of atrial fibrosis formation and a potential contributor to the evolution of structural remodeling in AF patients. They reported that miR-21 is increased in left atria of AF patients and is associated with reduced expression of the cysteinerich signaling protein Sprouty1, which is an endogenous suppressor of fibroblasts ERK-MAP signaling. Using cardiac fibroblasts they also demonstrated that the increase in miR-21 and the decrease in Sproutyl could be reproduced by activation of a small GTPase of the Rho family (Rac1), connective-tissue growth-factor (CTGF) and lysyl oxidase with angiotensin-II. They also showed that overexpression 
of lysyl oxidase resulted in enhanced expression of Droscha and Dicer, two important endonucleases for miR formation, mechanistically linking lysyl oxidase and miR-21 formation. Moreover, Rac1 overexpressing mice, which develop spontaneous AF at older age [1], exhibited increased atrial levels of miR-21, decreased Sprouty 1 expression and elevated CTGF, lysyl oxidase and atrial fibrosis. Most importantly, inhibition of Rac1 with statins reduced atrial fibrosis, likely because of decreased miR-21 levels with concomitant increases in Sprouty1 expression. Finally, they showed that inhibition of miR-21 with chemically modified antisense oligonucleotides specific for miR-21 (antagomir-21) prevented atrial fibrosis secondary to myocardial infarction, suggesting that the direct silencing of miR-21 by antagomirs might be a potential therapeutic option to target atrial fibrosis in AF patients.

The elegant study of Adam et al. [2] adds miR-21 to the growing list of miRs implicated in the fundamental AF mechanisms (Fig. 1). The reentry-promoting shortening of the action potential duration is largely due to reduced L-type $\mathrm{Ca}^{2+}$ current and enhanced inward-rectifier $\left(I_{\mathrm{K} 1}\right.$ and a constitutive form of the acetylcholine-gated $\left.I_{\mathrm{K}, \mathrm{ACh}}\right)$ and slow delayed-rectifier $\left(I_{\mathrm{Ks}}\right) \mathrm{K}^{+}$currents [3, 7, 10]. Although the molecular basis of these ion current abnormalities is multifactorial [35], there is evidence for involvement of altered miR expression in all of these current abnormalities (Fig. 1). Repressed translation of $\alpha_{1 \mathrm{C}}$ (Cav1.2) and $\beta_{1}(\operatorname{Cav} \beta 1) I_{\mathrm{Ca}, \mathrm{L}}$ subunits by enhanced miR328 is one potential mechanism of reduced $I_{\mathrm{Ca}, \mathrm{L}}$ in human $\mathrm{AF}$ [21]. The KCNQ1 gene encoding the major $I_{\mathrm{Ks}}$ channel subunit contains putative binding sites for miR-1, which potentially links reduced miR-1 [13] levels with enhanced $I_{\mathrm{Ks}}$ current in AF patients [3]. Reduced levels of miR-1 [13], miR-26 and miR-101 [22], which repress expression of the principal $I_{\mathrm{K} 1}$ subunit Kir2.1 (KCNJ2), enhance Kir2.1 proteins levels contributing to the larger $I_{\mathrm{K} 1}$ in human AF [34]. Recent work identified $\mathrm{Na}^{+}-\mathrm{Ca}^{2+}$ exchanger 1 (NCX1) as a novel target of miR-1 [17], suggesting that deregulated miR-1 may contribute to the higher NCX expression and function in AF patients [14]. However, reduced miR-1 is not a consistent finding in AF, because unaltered [21] and enhanced miR-1 levels [4] have also been reported. The reason for these inconsistent findings in atrial miR levels among studies is not known, but might reflect use of right versus left atrial tissue and differences in age, concomitant diseases and medication in the studied patient populations [5, 12, 29]. Interestingly, overexpression of miR-1 enhances the incidence of spontaneous sarcoplasmic reticulum (SR) $\mathrm{Ca}^{2+}$-release events by increasing steady-state S2814 phosphorylation of type- 2 ryanodine receptor channels (RyR2) through a selective miR-1-induced decrease in B56 $\alpha$ expression, which targets the protein phosphatase 2A (PP2A) to specific subcellular microdomains [30]. Myocytes from AF patients show S2814-hyperphosphorylated RyR2 and a higher incidence of spontaneous SR $\mathrm{Ca}^{2+}$-release events and delayed afterdepolarizations leading to triggered activity/abnormal automaticity $[11,33]$. This points to the possibility that the hyperphosphorylation-mediated RyR2 dysfunction in AF patients may at least in part result from increased miR-1
Fig. 1 Schematic highlighting putative contribution of altered atrial $\mathrm{miR}$ expression to established fundamental mechanisms of AF. $I_{C a, L}$ L-type $\mathrm{Ca}^{2+}$ current, $I_{K l}$ inwardrectifier $\mathrm{K}^{+}$current, $I_{K s}$ slow delayed-rectifier $\mathrm{K}^{+}$current, TRPC3 transient-receptor potential $C$ type- 3 channel, $R y R 2$ ryanodine-receptor type2, $N C X 1 \mathrm{Na}^{+}-\mathrm{Ca}^{2+}$ exchanger type-1, $P P 2 A$ protein phosphatase $2 \mathrm{~A}, B 56 \alpha 56 \mathrm{kDa}$ regulatory subunit alpha of PP2A, ERP effective refractory period, $D A D s$ delayed afterdepolarizations. The miR identified by Adam et al. [2] as a critical regulator of atrial fibrosis formation (miR-21) is underlined

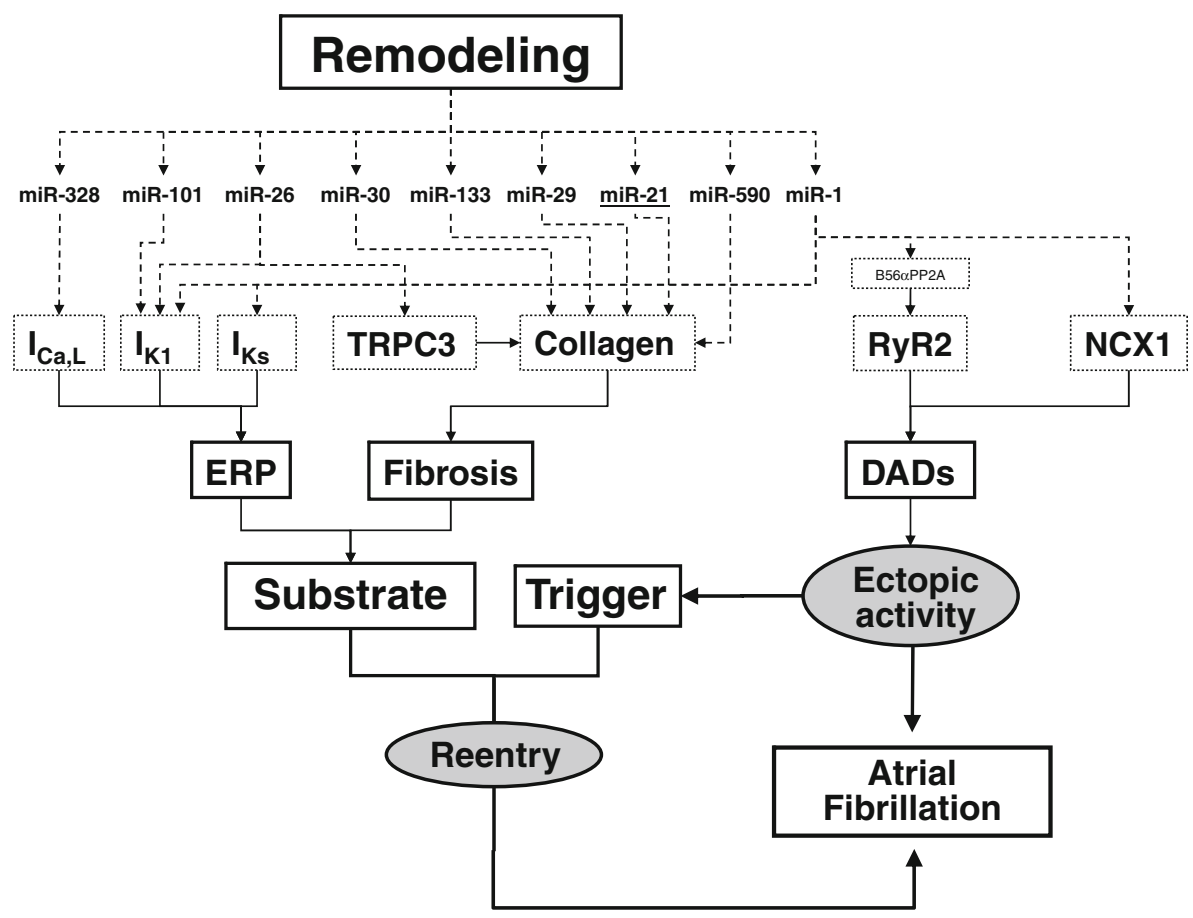


levels, which may decrease PP2A activity within the RyR2 macromolecular complex despite the global increase of PP2A activity in AF patients [15].

In addition to electrical and $\mathrm{Ca}^{2+}$-handling remodeling, miRs also promote structural remodeling in AF. Shan et al. [28] showed that downregulation of miR-133 and miR-590 contributes to nicotine-induced atrial structural remodeling in canines. The downregulation of these two antifibrotic miRs significantly increased the protein levels of transforming growth-factor $\beta_{1}$ (TGF- $\beta_{1}$ ) and its type-II receptor, and enhanced collagen production. The profibrotic mediator TGF- $\beta_{1}$ is secreted by both fibroblasts and cardiomyocytes and cardiac-overexpression of constitutively-active TGF- $\beta_{1}$ causes selective atrial fibrosis and conduction heterogeneity, increasing AF susceptibility [32]. miR-29 inhibits collagen genes and miR-29 downregulation likely contributes to atrial fibrosis in heart failure [6]. CTGF is a downstream mediator of TGF- $\beta_{1}$ profibrotic signaling and miR-30 and miR-133, which suppress CTGF production, are downregulated in chronic $\mathrm{AF}$ [18]. In addition, recent work suggests that $\mathrm{Ca}^{2+}$-entry through non-selective transient-receptor potential (TRP) C type-3 (TRPC3) channels is central to AF-related fibroblast activation [16]. Fibroblast TRPC3 expression is increased in $\mathrm{AF}$, mediates angiotensin-II-induced $\mathrm{Ca}^{2+}$ influx and promotes fibroblast proliferation and differentiation [16]. Moreover, TRPC3-expression is controlled by miR-26 [16], creating a mechanistic link between signaling pathways affecting electrical and structural remodeling. The present study of Adam et al. [2] extends these findings by being the first to show that miR-21 is an important contributor to atrial fibrosis and structural remodeling in $\mathrm{AF}$ patients. This paper also points to new therapeutic options to prevent structural remodeling by targeting miR-21 and the related signaling involving activation of TGF- $\beta_{1}$, CTGF, Rac1 and lysyl oxidase pathways.

Taken together, the emerging role of miRs in AF-promoting atrial remodeling presents potentially exciting therapeutic opportunities. miRs are stable in blood and interventions have been developed to enhance or suppress the expression of miRs involved in disease progression [27]. The apparent participation of miRs in the fundamental AF mechanisms, including APD reduction, abnormal SR $\mathrm{Ca}^{2+}$ release, and tissue fibrosis points to potential novel mechanism-based therapeutic targets. Finally, better insights into the molecular basis of AF may allow to identity AF biomarkers [23], thus helping to develop personalized therapeutic approaches.

Acknowledgments The author's work is supported by the European Network for Translational Research in Atrial Fibrillation (EUTRAF, Grant 261057), the German Federal Ministry of Education and Research (AF Competence Network and German Center for Cardiovascular Research), the Deutsche Forschungsgemeinschaft (Do 769/1-
3), and by a grant from Fondation Leducq (European-North American Atrial Fibrillation Research Alliance, Grant 07CVD03). The author is also thankful to Jordi Heijman for critical reading and his help with the figure.

\section{References}

1. Adam O, Frost G, Custodis F, Sussman MA, Schäfers HJ, Böhm M, Laufs U (2007) Role of Rac1 GTPase activation in atrial fibrillation. J Am Coll Cardiol 50:359-367. doi:org/10.1016/ j.jacc.2007.03.041

2. Adam O, Löhfelm B, Thum T, Gupta SK, Puhl SL, Schäfers HJ, Böhm M, Laufs U (2012) Role of miR-21 in the pathogenesis of atrial fibrosis. Basic Res Cardiol (in this issue)

3. Caballero R, de la Fuente MG, Gomez R, Barana A, Amoros I, Dolz-Gaiton P, Osuna L, Almendral J, Atienza F, FernándezAvilés F, Pita A, Rodríguez-Roda J, Pinto A, Tamargo J, Delpón E (2010) In humans, chronic atrial fibrillation decreases the transient outward current and ultrarapid component of the delayed rectifier current differentially on each atria and increases the slow component of the delayed rectifier current in both. J Am Coll Cardiol 55:2346-2354. doi:10.1016/j.jacc.2010.02.028

4. Chinchilla A, Daimi H, Lozano-Velasco E, Dominguez JN, Caballero R, Delpón E, Tamargo J, Cinca J, Hove-Madsen L, Aranega AE, Franco D (2011) PITX2 insufficiency leads to atrial electrical and structural remodeling linked to arrhythmogenesis. Circ Cardiovasc Genet 4:269-279. doi:10.1161/CIRCGENETICS.110.958116

5. Cooley N, Cowley MJ, Lin RC, Marasco S, Wong C, Kaye DM, Dart AM, Woodcock EA (2012) Influence of atrial fibrillation on microRNA expression profiles in left and right atria from patients with valvular heart disease. Physiol Genomics 44:211-219. doi: 10.1152/physiolgenomics.00111.2011

6. Dawson K, Wakili R, Ordog B, Clauss S, Qi XY, Cardin S, Kääb S, Nattel S (2010) Potential role of microRNA-29b in atrial fibrillation-promoting fibrotic remodeling. Circulation 122:A12545 (abstract)

7. Dobrev D (2006) Electrical remodeling in atrial fibrillation. Herz 31:108-112. doi:10.1007/s00059-006-2787-9

8. Dobrev D, Carlsson L, Nattel S (2012) Novel molecular targets for atrial fibrillation therapy. Nat Rev Drug Discov 11:275-291. doi: $10.1038 / \mathrm{nrd} 3682$

9. Dobrev D, Nattel S (2010) New antiarrhythmic drugs for treatment of atrial fibrillation. Lancet 375:1212-1223. doi:10.1016/ S0140-6736(10)60096-7

10. Dobrev D, Ravens U (2003) Remodeling of cardiomyocyte ion channels in human atrial fibrillation. Basic Res Cardiol 98:137148. doi:10.1007/s00395-003-0409-8

11. Dobrev D, Voigt N, Wehrens X (2011) The ryanodine receptor channel as a molecular motif in atrial fibrillation: pathophysiological and therapeutic implications. Cardiovasc Res 89:734-743. doi: $10.1093 / \mathrm{cvr} / \mathrm{cvq} 324$

12. Gaborit N, Steenman M, Lamirault G, Le Meur N, Le Bouter S, Lande G, Léger J, Charpentier F, Christ T, Dobrev D, Escande D, Nattel S, Demolombe S (2005) Human atrial ion channel and transporter subunit gene-expression remodeling associated with valvular heart disease and atrial fibrillation. Circulation 112:471481. doi:10.1161/CIRCULATIONAHA.104.506857

13. Girmatsion Z, Biliczki P, Bonauer A, Wimmer-Greinecker G, Scherer M, Moritz A, Bukowska A, Goette A, Nattel S, Hohnloser SH, Ehrlich JR (2009) Changes in microRNA-1 expression and $I_{\mathrm{K} 1}$ up-regulation in human atrial fibrillation. Heart Rhythm 6:1802-1809. doi:10.1016/j.hrthm.2009.08.035

14. Grandi E, Pandit SV, Voigt N, Workman AJ, Dobrev D, Jalife J, Bers DM (2011) Human atrial action potential and $\mathrm{Ca}^{2+}$ model: 
sinus rhythm and chronic atrial fibrillation. Circ Res 109:10551066. doi:10.1161/CIRCRESAHA.111.253955

15. Greiser M, Halaszovich CR, Frechen D, Boknik P, Ravens U, Dobrev D, Lückhoff A, Schotten U (2007) Pharmacological evidence for altered src kinase regulation of $\mathrm{ICa}, \mathrm{L}$ in patients with chronic atrial fibrillation. Naunyn Schmiedeberg's Arch Pharmacol 375:383-392. doi:10.1007/s00210-007-0174-6

16. Harada M, Luo X, Qi XY, Xiao J, Shi Y, Tardif JC, Nattel S (2011) MicroRNA26 regulation of TRPC3 subunits underlies profibrillatory fibroblast activation in a canine atrial fibrillation model. Circulation 124:A9739 (abstract)

17. Kumarswamy R, Lyon AR, Volkmann I, Mills AM, Bretthauer J, Pahuja A, Geers-Knörr C, Kraft T, Hajjar RJ, Macleod KT, Harding SE, Thum T (2012) SERCA2a gene therapy restores microRNA-1 expression in heart failure via an Akt/FoxO3Adependent pathway. Eur Heart J 33:1067-1075. doi:10.1093/ eurheartj/ehs043

18. Li H, Li S, Yu B, Liu S (2012) Expression of miR-133 and miR30 in chronic atrial fibrillation in canines. Mol Med Report 5:1457-1460. doi:10.3892/mmr.2012.831

19. Lloyd-Jones DM, Wang TJ, Leip EP, Larson MG, Levy D, Vasan RS, D'Agostino RB, Massaro JM, Beiser A, Wolf PA, Benjamin EJ (2004) Lifetime risk for development of atrial fibrillation: the Framingham Heart Study. Circulation 110:1042-1046. doi: 10.1161/01.CIR.0000140263.20897.42

20. Lorenzen JM, Martino F, Thum T (2012) Epigenetic modifications in cardiovascular disease. Basic Res Cardiol 107:245. doi: 10.1007/s00395-012-0245-9

21. Lu Y, Zhang Y, Wang N, Pan Z, Gao X, Zhang F, Zhang Y, Shan H, Luo X, Bai Y, Sun L, Song W, Xu C, Wang Z, Yang B (2010) MicroRNA-328 contributes to adverse electrical remodeling in atrial fibrillation. Circulation 122:2378-2387. doi:10.1161/ CIRCULATIONAHA.110.958967

22. Luo X, Pan Z, Xiao J, Zhang J, Lu Y, Yang B, Wang Z (2010) Critical role of microRNAs miR-26 and miR-101 in atrial electrical remodeling in experimental atrial fibrillation. Circulation 122:A19435 (abstract)

23. Meder B, Keller A, Vogel B, Haas J, Sedaghat-Hamedani F, Kayvanpour E, Just S, Borries A, Rudloff J, Leidinger P, Meese E, Katus HA, Rottbauer W (2011) MicroRNA signatures in total peripheral blood as novel biomarkers for acute myocardial infarction. Basic Res Cardiol 106:13-23. doi:10.1007/s00395010-0123-2

24. Mendell JT, Olson EN (2012) MicroRNAs in stress signaling and human disease. Cell 148:1172-1187. doi:org/10.1016/j.cell. 2012.02.005

25. Nattel S, Burstein B, Dobrev D (2008) Atrial remodeling and atrial fibrillation: mechanisms and implications. Circ Arrhythm Electrophysiol 1:62-73. doi:10.1161/CIRCEP.107.754564

26. Nattel S, Dobrev D (2012) The multidimensional role of calcium in atrial fibrillation pathophysiology: mechanistic insights and therapeutic opportunities. Eur Heart J. doi:10.1093/eurheartj/ ehs079 (published online on 16.04.2012)

27. Ohtani K, Dimmeler S (2011) Control of cardiovascular differentiation by microRNAs. Basic Res Cardiol 106:5-11. doi: 10.1007/s00395-010-0139-7

28. Shan H, Zhang Y, Lu Y, Zhang Y, Pan Z, Cai B, Wang N, Li X, Feng T, Hong Y, Yang B (2009) Downregulation of miR-133 and miR-590 contributes to nicotine-induced atrial remodelling in canines. Cardiovasc Res 83:465-472. doi:10.1093/cvr/cvp130

29. Suenari K, Chen YC, Kao YH, Cheng CC, Lin YK, Chen YJ, Chen SA (2011) Discrepant electrophysiological characteristics and calcium homeostasis of left atrial anterior and posterior myocytes. Basic Res Cardiol 106:65-74. doi:10.1007/s00395010-0132-1

30. Terentyev D, Belevych AE, Terentyeva R, Martin MM, Malana GE, Kuhn DE, Abdellatif M, Feldman DS, Elton TS, Györke S (2009) miR-1 overexpression enhances $\mathrm{Ca}^{2+}$ release and promotes cardiac arrhythmogenesis by targeting PP2A regulatory subunit B56alpha and causing CaMKII-dependent hyperphosphorylation of RyR2. Circ Res 104:514-521. doi:10.1161/ CIRCRESAHA.108.181651

31. Thum T, Gross C, Fiedler J, Fischer T, Kissler S, Bussen M, Galuppo P, Just S, Rottbauer W, Frantz S, Castoldi M, Soutschek J, Koteliansky V, Rosenwald A, Basson MA, Licht JD, Pena JT, Rouhanifard SH, Muckenthaler MU, Tuschl T, Martin GR, Bauersachs J, Engelhardt S (2008) MicroRNA-21 contributes to myocardial disease by stimulating MAP kinase signalling in fibroblasts. Nature 456:980-984. doi:10.1038/nature07511

32. Verheule S, Sato T, Everett T, Engle SK, Otten D, Rubart-von der Lohe M, Nakajima HO, Nakajima H, Field LJ, Olgin JE (2004) Increased vulnerability to atrial fibrillation in transgenic mice with selective atrial fibrosis caused by overexpression of TGFbeta1. Circ Res 94:1458-1465. doi:10.1161/01.RES.0000129579. $59664.9 \mathrm{~d}$

33. Voigt N, Li N, Wang Q, Wang W, Trafford AW, Abu-Taha I, Sun Q, Wieland T, Ravens U, Nattel S, Wehrens XH, Dobrev D (2012) Enhanced sarcoplasmic reticulum $\mathrm{Ca}^{2+}$-leak and increased $\mathrm{Na}^{+}$$\mathrm{Ca}^{2+}$-exchanger function underlie delayed afterdepolarizations in patients with chronic atrial fibrillation. Circulation 125:20592070. doi:10.1161/CIRCULATIONAHA.111.067306

34. Voigt N, Trausch A, Knaut M, Matschke K, Varro A, Van Wagoner DR, Nattel S, Ravens U, Dobrev D (2010) Left-to-right atrial inward-rectifier potassium current gradients in patients with paroxysmal versus chronic atrial fibrillation. Circ Arrhythmia Electrophysiol 3:472-480. doi:10.1161/CIRCEP.110.954636

35. Wakili R, Voigt N, Kaab S, Dobrev D, Nattel S (2011) Recent advances in the molecular pathophysiology of atrial fibrillation. J Clin Invest 121:2955-2968. doi:10.1172/JCI46315

36. Wang Z, Lu Y, Yang B (2011) MicroRNAs and atrial fibrillation: new fundamentals. Cardiovasc Res 89:710-721. doi:10.1093/ $\mathrm{cvr} / \mathrm{cvq} 350$ 